\title{
Comparing the Intensities and Spectral Resolution Achieved by Wavelength- Dispersive Spectrometers on Microprobes and SEMs.
}

\author{
Stephen M. Seddio ${ }^{1}$ and John J. Donovan ${ }^{2}$ \\ 1. Thermo Fisher Scientific, Fitchburg, WI, USA. \\ 2. CAMCOR, University of Oregon, Eugene OR, USA.
}

Recently, there has been much discussion regarding whether quantitative X-ray microanalysis by EDS has achieved the accuracy and precision yielded by traditional EPMA (e.g., [1]). In the most recent of these comparative studies [2], WDS analysis was done using an electron microprobe and EDS analysis was done using an SDD-EDS on an SEM. Here, we compare the accuracy and precision achieved by quantitative microanalysis using concurrently acquired WDS and EDS measurements.

Quantitative compositions were determined using the Cameca SX100 at the University of Oregon, which has five Rowland circle wavelength-dispersive spectrometers - three contain low-pressure P10 flow-though detectors and two contain high-pressure P10 flow-though detectors-and a Thermo Scientific UltraDry EDS, and the Probe for EPMA software [3]. All measurements were made using a $15 \mathrm{kV}$ accelerating voltage, a $30 \mathrm{nA}$ beam current, and a beam diameter of $10 \mu \mathrm{m}$. Standardization was done using synthetic $\mathrm{MgO}$ for $\mathrm{Mg} \mathrm{K} \alpha$, labradorite (Lake Co.) for $\mathrm{Al} \mathrm{K \alpha}$, synthetic $\mathrm{SiO}_{2}$ for $\mathrm{Si} \mathrm{K} \alpha$, diopside (Chesterman) for $\mathrm{Ca} \mathrm{K} \alpha$, and magnetite (Port Henry, U.C. \#3380) for Fe Ka. The following standards were analyzed as unknown samples for $\mathrm{Mg} \mathrm{K} \alpha, \mathrm{Al} \mathrm{K \alpha}$, $\mathrm{Si} \mathrm{K} \alpha, \mathrm{Ca} \mathrm{K \alpha}$, and $\mathrm{Fe} \mathrm{K \alpha}$ : synthetic $\mathrm{TiO}_{2}$, synthetic $\mathrm{MnO}$, synthetic $\mathrm{NiO}$, synthetic $\mathrm{Mg}_{2} \mathrm{SiO}_{4}$ (forsterite), NBS K-411, NBS K-412, VG-A99 USNM 113498/1, and orthoclase (MAD-10). Standard (primary and secondary) intensities were corrected for deadtime. Standard intensities were corrected for standard drift over time. In cases in which "unknown" samples contain unanalyzed elements, these elemental concentrations were entered as fixed concentrations for the matrix corrections. The synthetic $\mathrm{TiO}_{2}, \mathrm{MnO}$, and $\mathrm{NiO}$ standards were analyzed to determine the ability of EDS and WDS to measure $0 \mathrm{wt} \%$. For WDS measurements, all elements were counted on peak for $60 \mathrm{~s}$. A TAP crystal was used for counting $\mathrm{Mg} \mathrm{K \alpha}$ and Al $\mathrm{K} \alpha$, a LPET crystal was used for counting $\mathrm{Si} \mathrm{K} \alpha$ and $\mathrm{Ca} \mathrm{K} \alpha$, and an $\mathrm{LiF}$ diffractor was used for counting $\mathrm{Fe}$ $\mathrm{K} \alpha$. For EDS measurements, spectra were collected with the time constant set to "auto", and deadtimes were typically kept below $30 \%$, in order to minimize the magnitude of the corrections made by peak deconvolution and sum peak removal algorithms. EDS spectra were acquired for $40 \mathrm{~s}$ of livetime. The K-lines were used for quantitative analysis by EDS. For calculating concentrations from WDS measurements, the backgrounds were calculated using both off peak and mean atomic number (MAN, [4]) methods. Off peak intensities were counted for $10 \mathrm{~s}$. The off peak correction method was linear for $\mathrm{Mg} \mathrm{K} \alpha, \mathrm{Si} \mathrm{K} \alpha, \mathrm{Ca} \mathrm{K} \alpha$, and $\mathrm{Fe} \mathrm{K} \alpha$ and exponential for $\mathrm{Al} \mathrm{K} \alpha$. We used ZAF or Phi-Rho-Z (Armstrong/Love-Scott [5]) for the matrix correction method and Henke (LINEMU.DAT) [6,7,8] for the mass absorption coefficients dataset for calculating concentrations from EDS and WDS data.

Results are summarized in Table 1. The results are the averages of ten analyses, and the 99\% CI WDS detection limits ranged from $0.012 \mathrm{wt} \%$ for $\mathrm{Si} \mathrm{K} \alpha$ to $0.050 \mathrm{wt} \%$ for $\mathrm{Fe} \mathrm{K} \alpha$.

In most cases, modern SDD-EDS is now closely rivaling the accuracy and precision achievable by WDS. However, WDS analysis is better, certainly more practical, for trace analysis (see the Al concentrations measured in the $\mathrm{TiO}_{2}$ standard in Table 1). The combination of integrated and concurrent EDS and WDS for quantitative analysis is now an appealing option in which major and minor elements could be analyzed by EDS and minor and trace elements could be analyzed by WDS. 
References:

[1] DE Newbury and NWM Ritchie, J. Mater. Sci. 50 (2015) p. 493.

[2] HA Lowers and PK Carpenter, Microsc. Microanal. 21 (2015) p. 1881.

[3] Probe Software, Inc.

[4] JJ Donovan and TN Tingle, J. Micro. Soc. Amer. 2 (1996) p. 1.

[5] JW Armstrong, Microbeam. Anal. 4 (1995) p. 177.

[6] KFJ Heinrich, The Electron Microprobe (1966).

[7] BL Henke and ES Ebisu, Adv. X-ray Anal. (1974).

[8] BL Henke, LBL X-ray Data Booklet (1985).

Table 1. WDS and EDS analyses

\begin{tabular}{|c|c|c|c|c|c|c|c|c|c|c|c|c|}
\hline \multirow[b]{3}{*}{$\mathrm{O}$} & \multicolumn{4}{|c|}{$\mathrm{TiO}_{2}$} & \multicolumn{4}{|c|}{$\mathrm{MnO}$} & \multicolumn{4}{|c|}{$\mathrm{NiO}$} \\
\hline & Publ. & MAN & Off-Pk & EDS & Publ. & MAN & Off-Pk & EDS & Publ. & MAN & Off-Pk & EDS \\
\hline & 40.05 & 40.05 & 40.05 & 40.05 & 22.55 & 22.55 & 22.55 & 22.55 & 21.42 & 21.42 & 21.42 & 21.42 \\
\hline $\mathrm{Mg}$ & 0 & -0.001 & -0.002 & 0.004 & 0 & 0.000 & 0.002 & 0.000 & 0 & 0.000 & 0.001 & 0.000 \\
\hline $\mathrm{Al}$ & 0.01 & 0.016 & 0.010 & 0.025 & 0 & -0.001 & 0.003 & 0.028 & 0 & 0.000 & 0.008 & 0.000 \\
\hline $\mathrm{Si}$ & 0 & 0.002 & 0.009 & 0.101 & 0 & -0.004 & 0.011 & 0.123 & 0 & 0.002 & 0.025 & 0.216 \\
\hline $\mathrm{Ca}$ & 0 & 0.001 & 0.000 & 0.000 & 0 & -0.001 & -0.002 & 0.001 & 0 & 0.000 & -0.001 & 0.006 \\
\hline $\mathrm{Ti}$ & 59.94 & 59.94 & 59.94 & 59.94 & 0 & - & - & - & 0 & - & - & - \\
\hline $\mathrm{Mn}$ & 0 & - & - & - & 77.45 & 77.45 & 77.45 & 77.45 & 0 & - & - & - \\
\hline $\mathrm{Fe}$ & 0 & 0.000 & 0.005 & 0.014 & 0 & 0.098 & 0.024 & 1.530 & 0 & 0.000 & 0.010 & 0.030 \\
\hline $\mathrm{Ni}$ & 0 & - & - & - & 0 & - & - & - & 78.58 & 78.58 & 78.58 & 78.58 \\
\hline \multirow[t]{3}{*}{ Sum } & 100 & 100.01 & 100.01 & 100.13 & 100 & 100.09 & 100.04 & 101.68 & 100 & 100.00 & 100.04 & 100.25 \\
\hline & \multicolumn{4}{|c|}{$\mathrm{Mg}_{2} \mathrm{SiO}_{4}$} & \multicolumn{4}{|c|}{ NBS K-411 } & \multicolumn{4}{|c|}{ NBS K-412 } \\
\hline & Publ. & MAN & Off-Pk & EDS & Publ. & MAN & Off-Pk & EDS & Publ. & MAN & Off-Pk & EDS \\
\hline $\mathrm{O}$ & 45.49 & 45.49 & 45.49 & 45.49 & 43.60 & 43.60 & 43.60 & 43.60 & 43.60 & 43.60 & 43.60 & 43.60 \\
\hline $\mathrm{Mg}$ & 34.55 & 34.72 & 34.71 & 34.71 & 8.85 & 8.88 & 8.87 & 8.80 & 11.66 & 11.77 & 11.76 & 11.55 \\
\hline $\mathrm{Al}$ & 0 & -0.002 & 0.003 & 0.000 & 0.053 & 0.025 & 0.022 & 0.081 & 4.91 & 4.90 & 4.90 & 5.00 \\
\hline $\mathrm{Si}$ & 19.96 & 19.85 & 19.83 & 20.39 & 25.38 & 25.32 & 25.30 & 24.66 & 21.20 & 21.10 & 21.09 & 21.14 \\
\hline $\mathrm{Ca}$ & 0 & 0.004 & 0.007 & 0.000 & 11.06 & 10.80 & 10.79 & 10.86 & 10.90 & 10.68 & 10.68 & 10.78 \\
\hline Mn & 0 & - & - & - & 0.077 & 0.077 & 0.077 & 0.077 & 0.062 & 0.062 & 0.062 & 0.062 \\
\hline $\mathrm{Fe}$ & 0 & 0.001 & 0.007 & 0.017 & 11.21 & 11.11 & 11.10 & 11.22 & 7.74 & 7.72 & 7.73 & 7.80 \\
\hline \multirow[t]{3}{*}{ Sum } & 100 & 100.06 & 100.04 & 100.59 & 100.2 & 99.81 & 99.76 & 99.30 & 100 & 99.83 & 99.82 & 99.93 \\
\hline & \multicolumn{4}{|c|}{ VG-A99 USNM 113498/1 } & \multicolumn{4}{|c|}{ Orthoclase (MAD-10) } & \multirow{15}{*}{\multicolumn{4}{|c|}{$\begin{array}{l}\text { All values are in wt\% and are } \\
\text { averages of } 10 \text { analyses. "Publ." } \\
\text { refers to the actual standard } \\
\text { composition. "MAN" refers to } \\
\text { WDS analyses calculated using } \\
\text { the MAN background method. } \\
\text { "Off-Pk" refers to WDS } \\
\text { analyses calculated using an } \\
\text { off-peak background method. } \\
\text { Italicized values are fixed. The } \\
\text { standard deviation of the WDS } \\
\text { analyses ranged from } 0.001 \text { to } \\
\text { 0.079. The standard deviation of } \\
\text { the EDS analyses ranged from } \\
\text { 0.001 to } 1.182 \text {. }\end{array}$}} \\
\hline & Publ. & MAN & Off-Pk & EDS & Publ. & MAN & Off-Pk & EDS & & & & \\
\hline $\mathrm{O}$ & 43.34 & 43.34 & 43.34 & 43.34 & 45.80 & 45.80 & 45.80 & 45.80 & & & & \\
\hline $\mathrm{Na}$ & 1.97 & 1.97 & 1.97 & 1.97 & 0.675 & 0.675 & 0.675 & 0.675 & & & & \\
\hline $\mathrm{Mg}$ & 3.06 & 3.03 & 3.03 & 3.00 & 0 & 0.001 & -0.001 & 0.036 & & & & \\
\hline $\mathrm{Al}$ & 6.61 & 6.47 & 6.46 & 6.61 & 8.85 & 8.77 & 8.77 & 8.81 & & & & \\
\hline $\mathrm{Si}$ & 23.81 & 23.57 & 23.55 & 23.51 & 30.29 & 30.26 & 30.23 & 30.16 & & & & \\
\hline $\mathrm{P}$ & 0.166 & 0.166 & 0.166 & 0.166 & 0 & - & - & - & & & & \\
\hline K & 0.681 & 0.681 & 0.681 & 0.681 & 12.86 & 12.86 & 12.86 & 12.86 & & & & \\
\hline $\mathrm{Ca}$ & 6.65 & 6.41 & 6.41 & 6.42 & 0 & 0.000 & -0.015 & 0.000 & & & & \\
\hline $\mathrm{Ti}$ & 2.43 & 2.43 & 2.43 & 2.43 & 0 & - & - & - & & & & \\
\hline $\mathrm{Mn}$ & 0.116 & 0.116 & 0.116 & 0.116 & 0 & - & - & - & & & & \\
\hline $\mathrm{Fe}$ & 10.34 & 10.17 & 10.17 & 10.28 & 1.46 & 1.36 & 1.36 & 1.28 & & & & \\
\hline $\mathrm{Ba}$ & 0 & - & - & - & 0.054 & 0.054 & 0.054 & 0.054 & & & & \\
\hline Sum & 99.17 & 98.35 & 98.32 & 98.52 & 99.99 & 99.78 & 99.73 & 99.68 & & & & \\
\hline
\end{tabular}

